\title{
O Exercício do Controle Social no Sistema Único de Saúde: a ótica do enfermeiro como membro do Conselho Local de Saúde'
}

Exercise of Social Control in Brazilian's National Health System: nurses' point of view as a member of Local Health Council

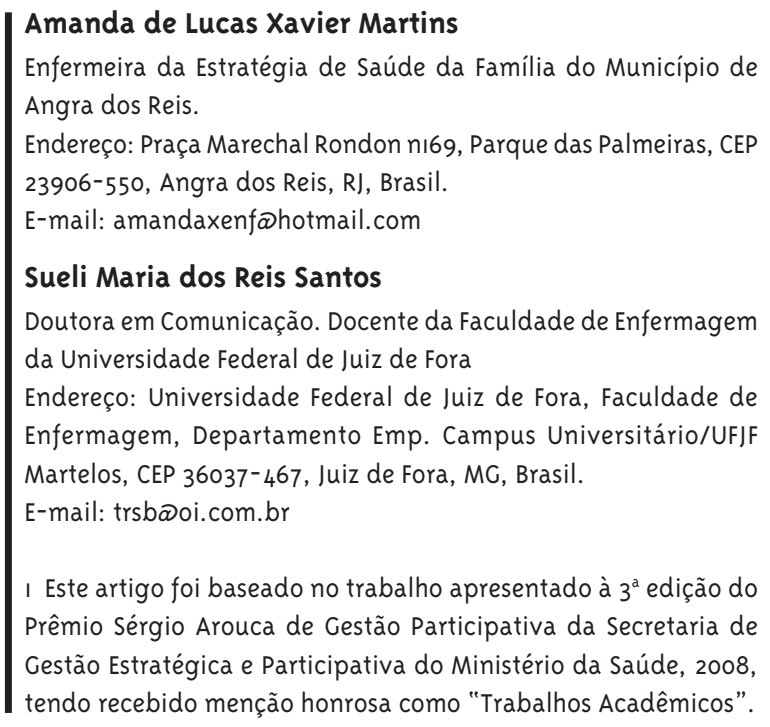

Enfermeira da Estratégia de Saúde da Família do Município de Angra dos Reis.

Endereço: Praça Marechal Rondon nı69, Parque das Palmeiras, CEP 23906-550, Angra dos Reis, RJ, Brasil.

E-mail: amandaxenfळhotmail.com

Sueli Maria dos Reis Santos

Doutora em Comunicação. Docente da Faculdade de Enfermagem da Universidade Federal de Juiz de Fora

Endereço: Universidade Federal de Juiz de Fora, Faculdade de Enfermagem, Departamento Emp. Campus Universitário/UFJF Martelos, CEP 36037-467, Juiz de Fora, MG, Brasil.

E-mail: trsbळoi.com.br

I Este artigo foi baseado no trabalho apresentado à $3^{\text {a }}$ edição do Prêmio Sérgio Arouca de Gestão Participativa da Secretaria de Gestão Estratégica e Participativa do Ministério da Saúde, 2008, tendo recebido menção honrosa como "Trabalhos Acadêmicos".

\section{Resumo}

0 estudo trata de conhecer o posicionamento do enfermeiro sobre sua atuação no Conselho Local de Saúde frente ao princípio organizacional do SUS de controle social no planejamento, acompanhamento e avaliação das ações de saúde. Realizou-se uma pesquisa qualitativa, do tipo exploratório descritivo; os dados foram coletados por meio de entrevistas com enfermeiros de Unidades Básicas de Saúde (UBS) de Juiz de Fora e atuantes nos Conselhos Locais de Saúde. Foram entrevistados 15 enfermeiros. A análise dos dados foi feita sob dois eixos: a opinião do enfermeiro em relação ao seu papel de Conselheiro Local de Saúde (CLS), tomando parte no exercício de controle social da gestão do SUS e quanto aos reflexos percebidos de sua participação, tanto no serviço de saúde (UBS) como na condição de saúde da comunidade. Resultados: a maioria dos entrevistados tem consciência da importância da atuação do CLS, e considera importante a participação do Enfermeiro no CLS, devido a sua formação voltada para a prática social e de saúde pública. No entanto, muitos entrevistados ainda acreditam que a atuação do Enfermeiro no CLS é importante somente como espaço para divulgar ações e necessidades do serviço de atenção básica à saúde.

Palavras-chave: Sistema Único de Saúde; Controle Social; Enfermagem. 


\section{Abstract}

The study tries and reveal nurses' point of view about their performance in Local Council of Health (CLS) in relation to the organizational principle of SUS of social control of the planning, monitoring and evaluation of the health unit's actions. A qualitative research of descriptive exploratory type was conducted; data were collected through interviews of nurses working at Basic Units of Health (UBS) of Juiz de Fora which were active in Local Council of Health. 15 nurses were interviewed, when saturation of data was reached. Analysis of data was made under two thought axes: the nurses' opinion in relation to their role as Local Counselor of Health, taking part in the social control of SUS' administration, and regarding the perceived reflexes of this participation at the health service (UBS) and over community health's conditions. Results: most of the interviewees is aware of the importance of the CLS and consider Nurse's participation at CLS important, due to their training in aspects of social practice and in public health. However, many interviewees still believe that the Nurse's acting in CLS is important only as space to publicize primary care services' actions and needs.

Keywords: National Health System; Social Control; Nursing.

\section{Introdução}

A $8^{\text {a }}$ Conferência Nacional de Saúde, realizada em Brasília em 1986, foi considerada um momento histórico em termos de democratização na área da saúde (Brasil, 1986).

A Reforma Sanitária constitui-se como um exemplo dessa experiência de democratização da saúde no Brasil; foi a partir dela que se introduziu na Constituição Brasileira de 1988 a determinação de que "a saúde é direito de todos e dever do Estado". (Brasil, 1988).

O Movimento da Reforma foi, também, responsável pela construção da idéia do Sistema Único de Saúde (SUS), concebido como um novo Sistema de Saúde com o propósito de ser o instrumento para garantir o cumprimento do "dever do Estado" de proporcionar saúde e bem-estar a todos os brasileiros. Naquele momento, o "controle social" foi considerado uma conquista, sendo a principal estratégia para garantir a descentralização e municipalização da saúde, objetivos centrais daquela Reforma.

Em 1991 foi sancionada a Lei $n^{\circ} 8.142 / 90$, que prevê a formação dos conselhos federal, estadual e municipal de saúde e a realização periódica de conferências nesses três níveis. Esta conquista democrática está à altura de um grande objetivo, que é assegurar a construção de um modelo assistencial intersetorial baseado na cidadania, em defesa da vida e da saúde, e com acesso universal e eqüitativo da coletividade, dos grupos populacionais expostos a riscos específicos e de cada indivíduo a todos os níveis da atenção integral à saúde.

No contexto da Enfermagem, desde o início da década de 1980 debate-se a perspectiva da formação de profissionais críticos, reflexivos, compromissados com seu papel social, que atuem como sujeitos ativos no seu próprio percurso de vida e de trabalho e contribuam para a construção de um sistema de saúde pautado nos princípios SUS; é desta época o início da construção de um projeto político para a profissão. Esse processo foi conduzido pela Associação Brasileira de Enfermagem (ABEn), e vem sendo implementado, enfrentando políticas econômicas, de ensino e de saúde nem sempre favoráveis aos processos de transformação (Barros e col., 1992). 
Dentre as diretrizes definidas nessa construção do projeto político tem-se a atribuição de defender a construção de um modelo de atenção que atenda às necessidades da população com base no perfil sócio econômico e epidemiológico, assegurando a presença do enfermeiro em órgãos deliberativos e/ ou Comissões e Estudos de formulação e decisão política (Barros e col., 1992).

Nessa linha de pensamento, foi possível observar de maneira mais próxima da realidade local a atuação dos Conselhos Locais de Saúde (CLS) como órgãos de "controle social”; estes conselhos, vinculados ao Conselho Municipal de Saúde (CMS) de Juiz de Fora, Minas Gerais, estão presentes nos locais em que há unidades básicas de saúde no município. Eles devem ser compostos em 70\% por representantes da comunidade (usuários), em 20\% por representantes dos trabalhadores de saúde e os $10 \%$ restantes por representantes do governo das respectivas Unidades Básicas de Saúde (UBS) (Regimento Interno dos Conselhos Locais e Regionais de Saúde de Juiz de Fora - MG, no Cap.III, Art. $4^{\circ}$ e $5^{\circ}$ ) (Minas Gerais, 1994).

As atribuições do CLS, descritas no Cap.V, Art. $7^{\circ}$ do Regimento Interno, visam garantir, dentre outras questões, o funcionamento adequado das UBS, elaborar propostas e programas que atendam às necessidades da população no setor da Saúde, à convocação de assembléias, promoção de debates em torno de problemas que afetam a comunidade, ao encaminhamento de reivindicações ao CMS, ao acompanhamento das aplicações dos recursos orçamentários constantes no Plano Municipal de Saúde destinado a consolidação dos Distritos Sanitários e dos Sistemas Locais de Saúde, finalmente a desenvolver junto às comunidades as noções básicas de Saúde, com a finalidade de melhorar a qualidade de vida e incentivar a participação da comunidade (Minas Gerais, 1994).

Segundo Barros e colaboradores (1992) a realidade brasileira revela que a maioria dos enfermeiros se insere nas unidades produtoras de serviços de saúde públicos ou privados, hospitalares ou ambulatoriais, aí ocupando posições de chefia nos vários níveis - de serviços, setores, unidades e outros.

Assim, o enfermeiro, muitas vezes gerentes dos serviços de saúde, tem condições de participar e estimular a participação da comunidade no CLS graças ao seu conhecimento sobre saúde coletiva; sua condição de proximidade com a comunidade contribui para que esta expresse suas necessidades. Desta forma, a participação do enfermeiro ajuda a transmitir conhecimentos quanto ao funcionamento do SUS à população, assim como informações sobre seus direitos e deveres. Além desse papel político, o profissional deve contribuir para o oferecimento a toda população, de forma indiscriminada, a garantia de uma assistência de enfermagem qualificada, isenta de riscos para os usuários e para os próprios trabalhadores.

A partir dessa reflexão, buscou-se conhecer a visão dos enfermeiros sobre seu papel em relação ao "controle social" como princípio do SUS. Assim, o objetivo desse trabalho foi identificar o posicionamento do enfermeiro sobre sua atuação no Conselho Local de Saúde, considerando-se, também, o papel do "controle social" em relação ao planejamento, acompanhamento e avaliação das ações de saúde. O estudo tenta identificar se e como o enfermeiro, em sua atuação como conselheiro, explicita suas concepções, suas motivações e perspectivas, assim como seus limites e potencialidades para, junto com a comunidade, contribuir para a efetivação do SUS, através de uma atuação que contribua para a efetividade dos Serviços de Saúde.

\section{o Controle Social (Direito do Cidadão) e a Construção do SUS}

Segundo os Textos Técnicos para Conselheiros de Saúde, de incentivo à participação popular e controle social no SUS, (Brasil, 1998), a sociedade brasileira tem uma história marcada pelo autoritarismo e pela exclusão. Desde a sua origem, a divisão entre “cidadãos" e "não cidadãos" marcou as relações sociais no país. Ao longo dos anos e das lutas populares pela cidadania, muitas conquistas foram alcançadas, particularmente no plano dos direitos civis e políticos.

Desta forma, no plano das relações sociais, a eliminação da distância hoje existente entre cidadãos e não cidadãos tem que começar pelo efetivo reconhecimento dos direitos universais. Cada pessoa tem que se reconhecer e reconhecer o outro 
como portador de direitos. Esse é um processo que apenas se inicia na sociedade brasileira, que por décadas se acostumou a aceitar os direitos sociais como privilégio de alguns (Brasil, 1998).

Para reverter essa situação, há que se construir sujeitos políticos e sociais, assim definidos por Barros (1998, p. 30):

O sujeito é o ser que atua, que age, que participa das decisões que o afetam, que luta para determinar quais são os seus direitos e exigir o que for necessário para que possa usufruí-los. Ser cidadão não é que outros - seja o Estado, sejam organizações da sociedade - nos concedam ou nos coloquem como alvo ou objeto de suas ações.

0 direito à saúde praticamente se confunde com o direito à vida (Barros, 1998). Ter saúde exige alimentação adequada, boas condições de trabalho, moradia digna, saneamento básico eficiente, meio ambiente protegido e bem conservado, possibilidade de lazer e informação; é, portanto, o resultado de um conjunto de determinantes. Garantir a saúde da população é tarefa de todas as áreas de governo e de toda a sociedade. No entanto, embora um sistema de saúde que funcione bem não seja suficiente para assegurar isso, o sistema de saúde pode oferecer um espaço de atuação a partir do qual se possa exigir e provocar as ações de outras áreas. O SUS é uma proposta nessa direção.

De acordo com o Ministério da Saúde (Brasil, 2002b, p. 25):

No início do século XX, os movimentos trabalhistas urbanos criaram as Caixas de Aposentadorias e Pensões, que são transformadas nos Institutos de Aposentadorias e Pensões - IAPs, com forte peso dos sindicatos de trabalhadores e entidades patronais, em relação ao Governo Federal, na sua organização e gestão, inclusive, da assistência médico-hospitalar.

Este pode ser considerado o primeiro "embrião" marcante para a posterior criação de mecanismos e instâncias de "controle social”; à época, os principais protagonistas deste controle foram os sindicatos urbanos. A partir dos anos 1970, momento de uma verdadeira explosão da migração populacional para as periferias das grandes cidades em conseqüência da enorme concentração da renda e desigualdade social (Brasil, 2002b), registrou-se a criação de um grande número de associações de moradores, entidades religiosas, movimentos feministas, entidades filantrópicas e outros grupos sociais, que passaram a exercer atividades e pressões de reivindicações específicas, especialmente de serviços de saúde, direcionadas principalmente para esfera pública. (Brasil, 2002b).

O "controle social" seria a resultante da articulação e da negociação dos interesses fracionados e específicos de cada segmento, a favor dos interesses e direitos de cidadania do conjunto da sociedade. Ao ser exercido pelo conjunto das entidades e instituições da sociedade organizada, tende a ser o controle mais efetivo e legítimo, a favor do conjunto da sociedade. (Brasil, 2002a).

A participação conjunta de profissionais de saúde, dirigentes sindicais e de órgãos públicos, intelectuais, parlamentares e de representantes de diversos movimentos sociais levou à formulação da proposta da "Reforma Sanitária", que foi resultado de um grande movimento denominado "Movimento Sanitário". Essa proposta constituiu a base de um novo sistema de saúde debatido pelo Congresso Constituinte de 1987/1988, e representou o fim de um sistema constituído e instalado durante os longos 21 anos do regime militar em nosso país. Esta proposta foi incorporada na Constituição Federal de 1988 na forma do Sistema Único de Saúde (Brasil, 2002a).

Segundo o Conselho Nacional de Saúde (1998), o controle social projetado para o SUS é uma conquista das mobilizações sociais e democráticas dos anos 8o, que se consolidaram na Constituição Federal de 88 e nas Leis 8.o8o/9o e 8.142/9o, mas não substitui o controle social exercido por movimentos da sociedade organizada, como os sindicatos, movimentos comunitários, de defesa do consumidor, de partidos políticos e outros. (Brasil, 1998).

\section{A Enfermagem e a Construção do Sistema Único de Saúde}

A regulamentação do SUS, através das Leis Orgânicas da Saúde 8.080/9o e 8.142/90, estabelece princípios e direciona a implantação de um modelo de atenção à saúde que priorize a descentralização, 
a universalidade, a integralidade da atenção e o controle social, ao mesmo tempo em que incorpora em sua organização o princípio da territorialidade para facilitar o acesso das demandas populacionais aos serviços de saúde (BRASIL, 1990a, 199ob).

Nascimento e Nascimento (2005, p. 3), em relação à reorganização do Sistema de Saúde Brasileiro, acreditam que a implementação dos princípios e diretrizes do SUS, garantidos nas Leis Orgânicas da Saúde 8o8o/9o e 8142/9o,

[...] requer mudanças institucionais para incorporar, na prática, as novas formas de gestão para a construção de um modelo assistencial fundamentado na Vigilância à Saúde, a partir da (re)orientação da Atenção Básica para (re)organizar a saúde em um contexto de maior complexidade até a Gestão Plena do Sistema Municipal da Saúde através da implantação do Programa Saúde da Família (PSF), em 1994, com o objetivo de organizar a prática assistencial. (Nascimento e Nascimento, 2005).

O PSF se propõe a organizar as práticas nas suas UBS, evidenciando o caráter multiprofissional e interdisciplinar das Equipes de Saúde da Família (ESF), com a prestação de atendimento integral nas especialidades básicas de saúde, numa base territorial delimitada e apoiando-se em serviços de referências para os níveis de maior complexidade de atenção à saúde. Esta organização possibilita o reconhecimento da saúde como um direito de cidadania, ao estimular a organização da comunidade e buscar o aprimoramento da participação e do controle social da população na área da saúde (Nascimento e Nascimento, 2005).

Barbosa e colaboradores (2004, p.10) afirmam que:

A Enfermagem é uma profissão que possui significativo contingente de profissionais atuando em diversos lugares e desenvolvendo as mais variadas funções dentro da área de saúde. A atuação da Enfermagem no contexto brasileiro acontece na maioria das vezes sem que as pessoas percebam o que realmente esses profissionais desenvolvem e qual é o seu potencial para a implantação, manutenção e desenvolvimento de políticas de saúde tanto em nível curativo quanto preventivo. Não se pode negar que a Enfermagem é o eixo principal para suportar qualquer política de saúde que tenha como objetivo uma assistência de qualidade.

Nascimento e Nascimento (2005, p. 5) questionam as condições para que o profissional enfermeiro possa acompanhar as transformações pela quais passa a sociedade, decorrentes da política nacional de saúde que exige cada vez mais um trabalhador comprometido com competência técnica, ética, comunicacional e política. Na implantação e organização dos serviços de saúde, o exercício da prática da Enfermagem, para estes autores pode ser definido como

... prática [...]resultante da expressão de modos de organização social, integra-se às práticas dos outros trabalhadores de saúde como um coletivo que responde pela produção de serviços de saúde. Portanto, a Enfermagem é uma prática social que está determinada socialmente.

A proposta de construção do SUS tem propiciado várias mudanças no âmbito dos serviços de saúde e do modelo de atenção em saúde. Neste sentido, a prática do enfermeiro passa por uma série de transformações, deslocando-se a sua atuação profissional da área curativa, individualizada, vinculada às instituições hospitalares, para a produção de serviços em Unidades Básicas de Saúde, com ênfase nas ações de promoção e proteção da saúde em bases coletivas, sendo a equipe de saúde a unidade produtora destas ações (Nascimento e Nascimento, 2005).

Pode se observar, numa perspectiva crítica/ analítica, que a importância da prática dos enfermeiros nas equipes de saúde da família também está relacionada aos aspectos de interação social a ela associados, tal como a promoção e participação em atividades coletivas que engajam a comunidade. Entendemos que esta interação dos membros da comunidade entre si e com os enfermeiros pode criar as bases para a transformação da realidade vivida Desta forma, propiciando a identificação das reais necessidades da população, priorização dos problemas e mobilização dos profissionais e da comunidade, poderão ser planejadas intervenções criativas e mais substantivas na qualidade de vida e condições de saúde desta.

Barros (1992) afirma que a enfermagem, entendida como uma prática social, carregada de valores 
e contradições, mas, sobretudo, de um compromisso com a emancipação humana para a vida e saúde, não pode realizar-se senão na perspectiva da complexidade das transformações do contexto social contemporâneo.

Nessa ótica é possível considerar que a atuação do Enfermeiro em Unidades Básicas de Saúde, com ou sem PSF, a partir da reorganização do modelo de saúde no Brasil, aproxima-se das necessidades da comunidade ao incorporar em sua organização o princípio da territorialidade, que busca facilitar o acesso e a legítima identificação das demandas existentes. No Conselho Local de Saúde das Unidades Básicas de Saúde pode ser efetivado o planejamento participativo das ações a serem realizadas pelo serviço, através do exercício do Controle Social, o que contribui para uma real mudança do modelo de atenção à saúde, de acordo com os princípios do SUS.

\section{Metodologia}

Foi realizado um estudo exploratório descritivo, tendo como sujeitos os enfermeiros atuantes nos Conselhos Locais de Saúde presentes em todas as Unidades Básicas de Saúde de Juiz de Fora - MG. Os dados foram coletados por meio de entrevistas.

O cenário de estudo escolhido foi composto por 41 Unidades Básicas de Saúde (UBS) do município de Juiz de Fora, que estão articuladas aos Conselhos Locais de Saúde. Dentre as 41 UBS, foi preciso comparecer a 13 Unidades Básicas de Saúde para atingir o ponto de saturação das respostas.

Como no período de coleta de dados era iminente a eleição de Conselheiros dos CLS, participaram da pesquisa: um enfermeiro que não atuava como conselheiro oficial, e sim como participante nas reuniões do CLS; sete enfermeiros que atuavam como conselheiros, mas aguardavam a eleição para legitimar sua continuidade como conselheiro representante profissional; sete enfermeiros que atuavam como representantes da gerência (governamental), num total de 15 enfermeiros.

Em conformidade com a metodologia qualitativa, os dados obtidos foram analisados através das informações apreendidas, emitidas a partir da aplicação de entrevista semi-estruturada com questões fechadas e abertas.
Esta pesquisa seguiu as determinações da ética na pesquisa em saúde, conforme Resolução 196, do Conselho Nacional de Saúde, de 10 de outubro de 1996, que determina as normas e diretrizes regulamentadoras de pesquisa com Seres Humanos. As determinações e princípios éticos foram seguidos. O projeto foi aprovado pelo Comitê de Ética em Pesquisa da Universidade Federal de Juiz de Fora, conforme parecer consubstanciado de $\mathrm{n}^{0} .037 / 2007$ (Brasil, 1996).

\section{Resultados e Discussão}

0 perfil dos entrevistados foi assim identificado: $73 \%$ dos enfermeiros(as) formaram-se há mais de dez anos, e 87\% têm no mínimo uma formação em pós-graduação, sendo desta a maioria (47\%) na área de Saúde Coletiva, especificamente em Programa de Saúde da Família. Todos trabalham em Unidades Básicas de Saúde, grande parte deles com ampla experiência nessa área de trabalho - em média sete anos de trabalho nessa instituição de saúde. Todos atuam nos Conselhos Locais de Saúde aproximadamente há quatro anos, sendo 53\% conselheiros representantes do governo (gerente da UBS), $40 \%$ conselheiros representantes profissionais e $7 \%$ participantes da reunião do CLS como ouvintes.

A percepção do enfermeiro quanto à importância da sua atuação no Conselho Local de Saúde se diferencia em função de suas concepções sobre as funções do conselheiro e sobre a prática profissional do cuidado de enfermagem, podendo este cuidado ser realizado através das reuniões com a participação da comunidade.

As categorias empíricas foram elaboradas através da análise das entrevistas; fez-se um recorte destacando os pontos mais significativos em cada uma delas, de forma a identificar a idéia central dos informantes a respeito da questão. As diferentes idéias centrais foram agrupadas por afinidade ou semelhança, o que permitiu a construção dos núcleos de pensamento relacionados a seguir.

Uma primeira categoria formada a partir da opinião dos enfermeiros diz respeito à importância da sua atuação nos CLS; a segunda categoria refere-se à participação da comunidade e do enfermeiro no CLS; a terceira categoria avalia a comunidade, o 
enfermeiro e o Conselho Local de Saúde frente às políticas definidas pelo Sistema Único de Saúde e as ações de saúde realizadas pela Unidade Básica de Saúde.

\section{A percepção do enfermeiro quanto à importância da sua atuação no Conselho Local de Saúde}

A partir da análise dos dados coletados através das questões quanto à motivação e contribuição esperada por sua atuação no CLS, pôde-se verificar que a maioria dos entrevistados considerou importante sua atuação como conselheiro e acredita ter contribuído para a melhoria das condições de saúde da comunidade e dos serviços prestados pela UBS. Tal melhoria ocorreu devido à aproximação dos profissionais de saúde com a comunidade, através das reuniões do CLS, como se depreende das seguintes respostas:

O enfermeiro possui maior ligação com a comunidade, fazendo melhor identificação das suas necessidades, podendo desta forma contribuir na realização de ações preventivas. (E. 3).

o Enfermeiro, além de realizar o trabalho assistencial, tem a formação para ter visão social, sendo fundamental sua participação no conselho. (E.9).

Os Conselhos de Saúde foram criados para identificar, fiscalizar e cobrar solução para os problemas da população, bem como deliberar sobre políticas públicas para a saúde. A função do conselheiro é negociar soluções, ou seja, discutir e buscar acordos entre os diferentes atores sociais, visando encontrar as melhores saídas para os problemas que afligem a população. Pôde-se observar de forma positiva que os entrevistados, em sua maioria, acreditam que sua atuação no CLS é relevante, especialmente devido a sua formação como enfermeiro:

O trabalho do enfermeiro no CLS é árduo, mas a categoria da enfermagem deve possuir um espaço no CLS, é uma conquista da profissão. (E.g).

Uma pequena parcela dos entrevistados acredita que a importância de sua atuação, tanto na melhoria das condições de saúde da comunidade como dos serviços prestados pela UBS, é devida ao fato de contribuir para a construção do SUS através da sugestão de ações adequadas às necessidades locais:
A importância é [...] poder [ser um] elo de ligação entre conselho, usuários e equipe de saúde, tentando equilibrar as ações do serviço de saúde e propostas vindas da comunidade... (E.1).

A educação que o enfermeiro pode passar para a população é muito boa, participando da construção do SUS e sua implantação. (E.13).

Foi possível verificar também que o enfermeiro atua de forma a conscientizar a população participante do CLS quanto à importância desta participação:

Olha, eu trabalho muito assim de orientar as pessoas a trabalharem no CLS, de participarem, de reivindicarem e não de utilizarem a política de uma forma não correta (E. 12).

Nessa ótica, o Controle Social e a participação do Enfermeiro no Conselho de Saúde aproximamse das necessidades da comunidade tendo em vista a identificação das necessidades e a melhoria das intervenções na situação de saúde comunitária através do planejamento participativo das ações a serem realizadas pelo serviço de saúde, contribuindo dessa forma para a implementação do SUS pautada nos seus princípios. E sendo notável a intenção de alguns dos entrevistados a atuarem no CLS para incorporar estes princípios e promover a sua real incorporação pautada nestes.

Foi possível observar que, para alguns dos entrevistados, a importância de sua atuação no CLS era traduzida exclusivamente pelo papel de divulgar, informar, orientar e conscientizar a comunidade quanto ao serviço prestado pela UBS:

A contribuição esperada é a de fazer com que os Conselheiros divulguem e apóiem as ações, principalmente as educativas, não atuando somente como fiscalizadores $(\varepsilon .1)$.

A importância é [..]grande [...], pois o enfermeiro está informado quanto a tudo da UBS... (E. 5).

\section{A participação da comunidade e do enfermeiro no CLS}

Com relação ao controle social na gestão do SUS, a maioria dos enfermeiros acredita que ele pode ser ampliado pela interação com a comunidade, que permitiria identificar suas necessidades e garantir 
os seus direitos de cidadania, diminuindo a desigualdade social; notou-se, também, uma preocupação com a questão dos recursos financeiros, como se pode observar nos relatos a seguir:

Através do Controle Social [é] que se consegue distribuir bem os recursos financeiros, sendo equânime com os incentivos distribuídos pelo governo (E. 11).

o Controle Social é importante para que você exerça política no bom sentido. E é uma forma da população gerenciar, saber, participar, conhecer aonde vão os recursos humanos, os financeiros, então todos os recursos do SUS ( $E$. 12).

A atuação do CLS é de cobrança do Serviço e das ações da UBS, realizam ações de manipulação contra a própria comunidade e denúncias inválidas contra o serviço da UBS (E. 1).

Segundo o Conselho Nacional de Saúde, descrito nos textos básicos para Gestão Municipal da Saúde (Brasil, 2001), de acordo com as atribuições legais do Conselho de Saúde, cabe ainda a consideração de uma atuação na formulação de estratégias dizendo respeito a uma postura combativa/ofensiva/criadora de construção de um novo modelo de saúde; e a atuação no controle da execução das políticas, a uma postura defensiva, contra os desvios e distorções.

Em outras respostas sobre a importância do Controle Social, foi possível identificar a consciência de alguns dos entrevistados sobre a contribuição deste na mudança do modelo de saúde assistencialista para o modelo democrático, sanitarista do SUS:

$\varepsilon$ o caminho para reverter o atual modelo de saúde de curativo para preventivo ( $(\varepsilon .3)$.

Quanto aos papéis exercidos pelos CLS e os conselheiros, observou-se que os enfermeiros acreditam que tanto um como os outros são representantes dos seus respectivos segmentos. Deram ênfase ao segmento da comunidade ou ao segmento dos profissionais de saúde, de forma a concretizarem suas reivindicações através da participação nas decisões:

Bom o papel do CLS é exatamente essa porção terminal que está ali na comunidade que tem essa política de gerir recursos, de participar da política no sentido de melhoria das condições de saúde da população e, além disso, também, adequando as necessidades locais ( $E$. 12).

Os enfermeiros entrevistados têm consciência da atuação do conselheiro de saúde como parceiro da unidade de saúde:

O Conselheiro tem o papel de tentar se envolver $e$ conhecer os problemas da UBS e ser parceiro buscando soluções para as dificuldades encontradas (E. 7).

No entanto, em alguns relatos dos entrevistados aponta-se para o despreparo dos conselheiros para atuarem nos CLS:

Conselheiro deve conhecer a realidade da comunidade, são poucos os envolvidos e com vontade realmente de realizar as ações do CLS (E.1).

Apesar dessa consciência sobre a atuação do CLS e dos conselheiros, ainda é possível identificar na fala de alguns entrevistados a resistência à função fiscalizadora do Conselho de Saúde, justificada por meio de referências ao despreparo do conselheiro e da comunidade, que acreditam não possuem clara percepção de como deveria ser sua atuação:

O CLS tem o papel muito mais que fiscalizador, mas sim de participação das decisões de saúde (E. 4).

o Conselheiro tem o papel de representar a comunidade, falta definição do que eles devem fazer, são muito fiscalizadores ( $\varepsilon$. 5$)$.

Parte da resistência à atuação dos conselheiros é atribuída em alguns casos a suas atitudes clientelistas, que beneficiam apenas a alguns ou que atendem a interesses partidários ou a ambições políticas pessoais do próprio conselho:

Conselheiro tem atuado muito mais por interesse político próprio e não está sempre atuando nas decisões tomadas e discutindo as mesmas ( $(\varepsilon .4)$.

O clientelismo é uma prática que tem que ser combatida com todo o rigor em nome da construção de uma democracia nova. O mesmo terá que ser feito quando houver privilégio e atitudes políticas com o objetivo de fortalecer partidos políticos, em detrimento de grupos que a eles se opõem. (Brasil, 2002a)

Em se tratando do papel que os Conselhos de Saúde exercem, espera-se que a atuação destes cumpra os objetivos de contribuir para a gestão do 
SUS, especialmente nos aspectos de:

- melhoria da situação de saúde da comunidade, sob o ângulo de riscos sociais e epidemiológicos,

- dos direitos de cidadania dos grupos populacionais e de cada indivíduo;

- nas prioridades das intervenções (ofertas de serviço) de promoção, proteção e recuperação da saúde e da coletividade e de grupos de risco;

- na formulação de diretrizes e estratégias para o processo de planejamento, compromissos de metas, orçamento e execução orçamentária;

- no acompanhamento e avaliação do processo de execução dos planos, do orçamento e do cumprimento de metas, em função dos resultados de impacto na saúde da população geral e dos grupos de risco e, finalmente,

- no âmbito das responsabilidades e atribuições legais do gestor; e recebimento, dos demais órgãos de gestão, de todas as informações necessárias ao cumprimento das atribuições legais do Conselho de Saúde, em relações de parceria e sinergismo. (Brasil, 2001).

Pode-se observar que a maioria dos entrevistados acredita que a atuação e o impacto do CLS ainda estão distantes do que se poderia almejar, de acordo com o papel a eles proposto pelo Ministério da Saúde. Isso ocorreria devido ao despreparo da população para atuar no CLS, conforme se depreende das afirmações que se seguem:

O CLS possui um reflexo muito pequeno, normalmente os assuntos a serem discutidos são levados pelos profissionais da UBS. Na comunidade o reflexo poderia ser maior se os Conselheiros fossem mais ativos (E. 4$)$.

... Na situação de saúde da comunidade o reflexo é pouco devido a pouca participação da própria comunidade (E. 7).

Alguns enfermeiros se sentem satisfeitos com impacto ("reflexo") exercido pela atuação do CLS no serviço de saúde, pela boa comunicação entre comunidade e UBS, como se depreende deste relato:

Percebo um reflexo positivo sim, com uma boa relação da UBS e Conselho a UBS só tem a ganhar com a harmonia entre o serviço e a comunidade.
O CLS tem muita abertura com a UBS sabendo de tudo que ocorre aqui $(\varepsilon$. 7$)$.

\section{A comunidade, o enfermeiro e o Conselho Local de Saúde frente às políticas definidas pelo Sistema Único de Saúde e as ações de saúde realizadas pela Unidade Básica de Saúde}

Um aspecto notado nas entrevistas diz respeito ao caráter de satisfação decorrente do apoio da comunidade nas ações prestadas pela UBS. De acordo com os princípios que fundamentam o CLS, os conselheiros não devem ser bem-vistos apenas pelo seu apoio nas decisões da UBS e sim pela sua atuação crítica sobre as decisões e sugestões dela oriundas, tendo o direito de apoiar ou não as propostas.

Frente às questões a respeito da importância do Controle Social, do papel do CLS e seus conselheiros, dos reflexos da atuação do CLS na comunidade e no serviço da UBS, foi verificada a tendência de se acreditar que a atuação do CLS é boa somente quando estes apóiam propostas e ações promovidas pela UBS, formando parceria com o serviço e até ajudando a desenvolver ações que são de responsabilidade do serviço de saúde, como, por exemplo, ações educativas:

Sinto um reflexo positivo pelo apoio do CLS nas ações educativas... (E. g).

Não percebo reflexo nenhum, o CLS não possui apoio e envolvimento algum com a UBS... (E. 8).

A atuação do CLS é de cobrança do Serviço e das ações da UBS, realizam ações de manipulação contra a própria comunidade e denúncias inválidas contra o serviço da UBS (E.1).

Os Conselhos de Saúde foram criados para defender os interesses de todos os usuários, independente da sua representação de segmento, na prática de políticas de saúde participando desses colegiados e criando oportunidades de se ouvir a voz dos usuários do SUS. Os problemas de saúde que afligem uma comunidade não são todos iguais. Os Conselhos devem proporcionar a convivência democrática de propostas, às vezes conflitantes. No consenso a ser buscado, devem prevalecer os princípios do SUS. O Conselheiro de Saúde tem que estar bem informado, disposto para discussão polêmica e com disponibilidade para 
participar fora das reuniões ordinárias, comissões e outras atividades imprescindíveis. (Brasil, 2002a).

Não são poucos os casos em que as Secretarias procuram criar Conselhos manipuláveis, de modo a se escapar do "Controle Social". Isso acontece em lugares onde a organização popular não é forte o bastante para fazer cumprir a lei. Em geral, o que se espera dos Conselheiros é a insubmissão e o exercício do livre poder de decisão no que diz respeito a suas atribuições. Assim, o Conselheiro não pode se intimidar diante de conflitos com o poder público, porque sua atuação é garantida por lei. O Conselho de Saúde é um colegiado que tem sua organização e atuação garantida por lei, mas só será legítimo e representativo se atuar com autonomia. (Brasil, 2002a). O Conselheiro não tem função executiva. Ele participa da formulação da política de saúde, acompanha e fiscaliza sua implantação, incluindo-se aí o encaminhamento das denúncias. Ele não é executivo na realização de ações que visem implantar a política de saúde ou agilizá-la. (Brasil, 2002a).

\section{Considerações Finais}

A contribuição do Enfermeiro para a melhoria da qualidade da assistência de enfermagem e na consolidação do SUS pode se dar através de sua atuação como Conselheiro de Saúde, no planejamento, acompanhamento e avaliação das ações de saúde e no engajamento em garantir melhor assistência à saúde da comunidade. É relevante que esta categoria profissional esteja ciente da importante contribuição que pode fazer junto à comunidade, aproximando a programação local das ações de saúde às suas necessidades e ampliando desta forma a efetividade do Serviço de Saúde.

Com a realização dessa pesquisa foi possível identificar traços que caracterizam o posicionamento de enfermeiros sobre sua atuação no Conselho Local de Saúde à luz do princípio organizacional do SUS de controle social no planejamento, acompanhamento e avaliação das ações de saúde. Entendemos que o exercício dessa atribuição é legítimo, tendo em vista que o enfermeiro participa da democratização na gestão do SUS, na operacionalização de uma efetiva integração como profissional da saúde e de enfermagem na formulação de políticas de saúde.
A participação do enfermeiro como conselheiro exige uma reflexão sobre a legitimidade de sua atuação, que deve ser crítica e, compromissada com seu papel social, contribuindo para a oferta de uma atenção à saúde efetiva e de qualidade e para a consolidação do SUS em seus princípios de universalidade, integralidade e equidade.

Foi possível compreender que o cuidado de enfermagem envolve um compromisso com o estar no mundo e o bem-estar da população; sua atuação contribui para a construção da história, do conhecimento e da vida. Diante das concepções de cuidado e a realização deste na Saúde Pública, verificou-se que esse cuidado pode e deve ocorrer também através da participação do enfermeiro em órgãos deliberativos, especificamente no Conselho Local de Saúde. A atuação nos CLS coloca-se como uma das formas de reivindicar e contribuir para uma assistência de qualidade para a comunidade, pois estes são instâncias nas quais é possível identificar com mais clareza as necessidades da população. A adequação dos serviços a estas necessidades resulta em maior satisfação dos usuários e melhoria da qualidade dos serviços prestados nas Instituições de Saúde.

A atuação do enfermeiro no CLS contribui para a compreensão dos determinantes sociais do processo saúde-doença, das práticas e saberes na área da saúde, das relações e articulações econômicosociais e políticas. Assim, exercendo sua prática social, para além de sua dimensão profissional e técnica, ou seja, de uma aplicação imediata e direta dos conhecimentos técnico-científicos, o enfermeiro pode compreender a dinâmica social, a inter-relação de cada âmbito de prática com os demais, seja na produção do conhecimento e da saúde nos processos decisórios na produção da saúde como cidadãos portadores de direitos.

Com todas as dificuldades aqui evidenciadas, pode-se afirmar que mesmo assim a atuação do CLS e dos conselheiros é significativa para a melhoria da condição de saúde da população. Cabe aos enfermeiros refletirem sobre a real proposta de um Conselho de Saúde, na medida em que este foi proposto para ser um instrumento de legitimação do SUS, representando uma forma nova de pensar e agir para programar as políticas de saúde. O Conselho seria um local de convivência e negociação na 
busca de consenso entre diferentes pontos de vista, mediados pela obediência aos princípios do SUS, e não um substitutivo que realize ações atribuídas ao serviço de saúde.

Sendo assim, uma das formas de garantir o direito à saúde e manter a dignidade do sujeito, inerentes ao cuidado de enfermagem, pode ser o exercício do controle social sobre as políticas de saúde. E, apesar de algumas concepções equivocadas quanto à importância desse controle através dos Conselhos Locais de Saúde observadas nessa pesquisa, acreditamos que a enfermagem está no caminho certo para realização do cuidado através deles.

\section{Referências}

BARBOSA, M. A. et al. Reflexões sobre o trabalho do enfermeiro em saúde coletiva. Revista Eletrônica de Enfermagem, Goiânia, v. 6, n. 1, p. o9-15, 2004. Disponível em: <http://www.fen.ufg. br/revista/revista6_1/pdf/f1_coletiva.pdf >. Acesso em: 15 maio 2010.

BARROS, E. O controle social e o processo de descentralização dos serviços de Saúde. In:BRASIL. Ministério da Saúde. Incentivo à participação popular e controle social no SUS: textos técnicos para Conselheiros de Saúde. 2. ed. Brasília: IEC, 1998.

BRASIL. Ministério da Saúde. Incentivo à participação popular e controle social no SUS: textos técnicos para Conselheiros de Saúde. 2. ed. Brasília: IEC, 1998.

BARROS, S. M. P. F. et al. Projeto Político da Enfermagem Brasileira: oficina de trabalho. Revista Brasileira de Enfermagem, Brasília, v. 45, n. 2/3, p. 98-104, abr./set. 1992.

BRASIL. Constituição Federal (1988). Brasília: Senado Federal, 1988.

BRASIL. Resolução n. ${ }^{\circ}$ 196, de 10 de outubro de 1996. Dispõe sobre a realização de pesquisas com seres humanos. Brasília, DF: Ministério da Saúde, 1996.
BRASIL. Ministério da Sáude. Relatório Final da VIII Conferência Nacional de Saúde. Brasília, DF: Ministério da Saúde, 1986.

BRASIL. Lei Federal no 8.o8o, de 19 de Setembro de 1990. Dispõe sobre as condições para a promoção, proteção e recuperação da saúde, a organização e o funcionamento dos serviços correspondentes e dá outras providências. Brasília, DF: Casa Civil, 199oa.

BRASIL. Lei Federal no 8.142, de 28 de Dezembro de 1990. Dispõe sobre a participação da comunidade na gestão do Sistema Único de Saúde (SUS\} e sobre as transferências intergovernamentais de recursos financeiros na área da saúde e dá outras providências. Brasília, DF: Casa Civil, 199ob.

BRASIL. Ministério da Saúde. Incentivo a participação popular e controle social no SUS: textos técnicos para conselheiros de saúde. 2. ed. Brasília: IEC, 1998.

BRASIL. Ministério da Saúde. Gestão Municipal de Saúde: textos básicos. Rio de Janeiro:

Ministério da Saúde, 2001.

BRASIL. Ministério da Saúde. Guia do conselheiro: curso de capacitação de conselheiros estaduais e municipais de Saúde. Brasília, DF: Ministério da Saúde, 2002a. (Série F. Comunicação e Educação em Saúde).

BRASIL. Ministério da Saúde. A prática do controle social: Conselhos de Saúde e Financiamento do SUS. Brasília, DF: Ministério da Saúde, 2002b.

MINAS GERAIS. (Prefeitura). Conselho Municipal de Saúde. Regimento interno dos Conselhos Locais e Regionais de Saúde. Juiz de Fora: Conselho Municipal de Saúde, 1994

NASCIMENTO, M. S.; NASCIMENTO, M. A. A. A prática da enfermeira no Programa de Saúde da Família: a interface da vigilância da saúde versus as ações programáticas em saúde. Ciência \& Saúde Coletiva, Rio de Janeiro, v. 10, n. 2, p. 333-345, abr./ jun., 2005. 